\title{
EVALUATION FOR THE EFFICIENCY OF EARLY SELECTION IN Acacia mangium SEEDLING SEED ORCHARDS BASED ON AGE TRENDS IN GENETIC PARAMETER
}

\author{
Arif Nirsatmanto ${ }^{1)}$, Susumu Kurinobu ${ }^{2)}$, Susumu Shiraishi ${ }^{3)}$
}

\begin{abstract}
The efficiency of early selection was evaluated based on age trend in genetic parameters using tree height data that was measured periodically repeatedly up to age 3 years of age in four seedling seed orchards of Acacia mangium at South Kalimantan, Indonesia. The four orchards were grouped into two populations based upon their provenances, namely: Papua New Guinea (PNG) and Far North Queensland-Australia (FNQ). A model for time trend of genetic parameters was developed by fitting regression equation to the estimates of variances and correlations using tree height data as an independent variable. In both populations, genetic variances and total phenotypic variances increased along with the mean height. Trend of individual heritability along the rotation ages were almost stable at around 0.19 for PNG, and gradually increased from 0.36 to 0.40 for FNQ. Trend of genetic correlations between selection age and rotation age increased rapidly starting at around 0.5 for PNG and 0.6 for FNQ, then exceeding 0.9 at age four years in both populations. Genetic gains due to indirect selection increased with age, in which the gains in FNQ were generally larger than those in PNG. Selection efficiency based on gain per year as a ratio of the gains from indirect selection to direct selection may conclude resulted the optimum age for selection at age two years old in both of PNG and FNQ population.
\end{abstract}

Keywords: Acacia mangium, age-age genetic correlation, genetic parameter, heritability, seedling seed orchards, selection efficiency

\section{INTRODUCTION}

Early selection is often practiced in seedling seed orchard establishments to give higher genetic gains per unit time than the direct selection at rotation age (Lambeth, 1980). It is well known that genetic gain by this type of selection is primarily dependent on the size of heritability and genetic correlation between selection age and rotation age (McKeand, 1988, Cotteril and Dean, 1988).

Many studies on age trend of genetic parameters for evaluating the efficiency of early selection in breeding population have been

${ }^{1}$ Center for Forest Biotechnology and Tree Improvement Research, Yogyakarta

${ }^{2}$ Forest Tree Breeding Center, Ibaraki 319-1301, Japan

${ }^{3}$ Faculty of Agriculture, Kyushu University, Fukuoka 812-8581, Japan conducted by several authors in a range of species, mostly in pines: loblolly pine (Xiang et al., 2003, Lambeth and Dill, 2001, Gwaze et al., 2000), radiata pine (King and Burdon, 1991, Cotteril and Dean, 1988), Scots pine (Jansson et al., 2003), Douglas-fir (Johnson et al., 1997) and lodgepole pine (Xie and Ying, 1996). In case of fast growing species, some studies have been reported for, especially in eucalypts: Eucalyptus globulus (Borralho et al., 1992), Eucalyptus teriticornis (Otegbeye, 1991). For With regard to Acacia mangium, age trend of genetic parameters and its effects to the expected gains in rotation age has not yet been reported.

In this study, age trends in genetic parameters in two populations of $A$. mangium were investigated by analyzing tree height data derived from periodical repeatedly measurement up to age 
3 years in four seedling seed orchards at South Kalimantan, Indonesia. General trend in genetic parameters were estimated using a model of time trend made from regression equation using tree height data as an independent variable, because the variances tend to be dependent to their mean height (Falconer, 1981). Then, the value amount of genetic gain by indirect selection and that by direct selection were calculated to determine the efficiency of early selection in seedling seed orchards. The seedling seed orchards used in this study were designed to capture three simultaneous purposes: as progeny test in the beginning for selection, as seed production after rouging, and as base population for the next generation.

\section{MATERIALS AND METHODS}

\section{A. Seedling Seed Orchards}

Two populations of $A$. mangium (hereinafter referred as PNG and FNQ population) were made up from grouping of four seedling seed orchards based on their provenances: namely AM005 and AM007 for the PNG, and AM006 and AM008 for the FNQ (Table 1). These four seedling seed orchards were established in South Kalimantan, Indonesia ( $3^{\circ} 58 \mathrm{~S}$ and $\left.114^{\circ} 38 \mathrm{E}\right)$. The soil type was ferrasols previously occupied by Imperata cylindrica. The average annual rainfall is 2,730 $\mathrm{mm}$ with pronounced dry season from May to September. The tested families in PNG population were 5765 open pollinated families of Papua New Guinea provenance, while in FNQ population were 5557 open pollinated families of Far North Queensland-Australia provenance (Table 1). Design of the orchards were randomized complete blocks, which initially laidout as four trees in a row plot of $10 \quad 12$ replications with a spacing of $4 \times 2 \mathrm{~m}$. Tree height was periodically measured at almost every four months in each orchard until age of 48 months. During this period, within-plot selections were practiced once in all orchards at 22 months after planting with basic culling rate of $25 \%-50 \%$. However, the actual rate of selection was higher than the basic culling rate owing to the mortality of trees caused by wind damage at over ages of 36 months. Therefore, except for calculating average height growth, the data measured at over ages 36 months were excluded from the subsequent analysis to obtain accurate estimation of genetic parameters.

Table 1. Location and altitude for the families tested in four seedling seed orchards

\begin{tabular}{crrrrrl}
\hline $\begin{array}{c}\text { Seedling } \\
\text { Seed } \\
\text { orchard }\end{array}$ & $\begin{array}{c}\text { Seedlot } \\
\text { code }^{a}\end{array}$ & $\begin{array}{c}\text { Tested } \\
\text { family }\end{array}$ & $\begin{array}{c}\text { Latitude } \\
(\mathrm{S})\end{array}$ & $\begin{array}{c}\text { Longitude } \\
(\mathrm{E})\end{array}$ & $\begin{array}{c}\text { Altitude } \\
(\mathrm{m})\end{array}$ & \multicolumn{1}{c}{ Name of location } \\
\hline AM005 & 16590 & 7 & 0831 & 14213 & 50 & Dimisisi, PNG \\
& 16990 & 11 & 0842 & 14152 & 30 & Derideri E Morehead, PNG \\
& 16991 & 25 & 0837 & 14154 & 25 & Gubam NE Morehead, PNG \\
& 16992 & 7 & 0838 & 14203 & 40 & Bimadebun, PNG \\
& 16994 & 7 & 0843 & 14155 & 25 & Arufi Village, PNG \\
& 16997 & 8 & 0837 & 14158 & 25 & Boite NE Morehead, PNG \\
AM006 & 16932 & 7 & 1244 & 14316 & 40 & 135K NNE Coen, FNQ \\
& 17701 & 23 & 1245 & 14317 & 37 & Claudie River, FNQ \\
& 18265 & 12 & 1244 & 14316 & 30 & Claudie River, FNQ \\
AM007 & 231 & 13 & 1244 & 14316 & 20 & Claudie River, FNQ \\
& 15644 & 7 & 0858 & 14308 & 18 & Oriomo, PNG \\
& 16938 & 23 & 0805 & 14258 & 12 & Kini WP, PNG \\
AM008 & 16971 & 27 & 0847 & 14252 & 45 & Wipim District WP, PNG \\
& 17702 & 7 & 1234 & 14312 & 25 & Pascoe River, FNQ \\
& 17946 & 22 & 1248 & 14318 & 20 & Claudie River, FNQ \\
& 229 & 14 & 1249 & 14317 & 10 & Claudie River, FNQ \\
& 230 & 10 & 1234 & 14316 & 40 & Cassowary CK, FNQ \\
& 499 & 4 & 1234 & 14309 & 20 & Pascoe River, FNQ \\
\hline
\end{tabular}

PNG, Papua New Guinea; FNQ, Far North Queensland

${ }^{a}$ Seedlots with five-digit codes were CSIRO's seedlots and those with the three digits were QFRI's collection 


\section{B. Genetic parameter estimation}

Analysis of variance and covariance were firstly calculated in each seedling seed orchard using individual data $\left(y_{i j k}\right)$ at each measurement with the following linear model:

$y_{i j k}=\mu+R_{i}+F_{j}+e_{j k}$

where, $\mu, R_{i}, F_{j}, e_{i j k}$ are the overall mean, the $i t h$ replication effects, the $j$ th family effects and the error associated with $y_{i j k}$, respectively. Replication is assumed as fixed-effect, while the family is designated as random effect. Since the two orchards grouped in each population consisted of families from the same provenance region, the covariance between the two populations of factors were assumed to be zero. Hence, variance and covariance components for the two populations were then estimated by; (i) pooling the sum of squares and sum cross of products, and degree of freedom, and then, (ii) equating the respective pooled mean squares and mean cross products to their expectations. The pooled estimated variance and covariance components were subsequently used to estimate the genetic parameters for the two populations (Woolaston et al, 1990, Hodge and Purnell, 1993, Leksono et al, 2006).

Additive genetic variances for each measurement were calculated as four times the family variance component, with assumption that open pollinated families analyzed here were half sibs (Falconer, 1981). Phenotypic variances were calculated as the sum of family variance component and that of error variance.

Individual tree heritabilities $\left(b_{i}^{2}\right)$ were calculated on each trait using the following formula (Zobel and Talbert, 1984):

$h_{i}^{2}=4 \sigma_{f}^{2} /\left[\sigma_{f}^{2}+\sigma_{e}^{2}\right]$

where, $\sigma_{f}^{2}, \sigma_{e}^{2}$, are estimates of variance component for family and error, respectively.

While, genetic correlations between the two different measurements $\left(r_{g i j}\right)$ were calculated as follows (Falconer 1981):

$r_{g i j}=\operatorname{cov}_{f(i j)} /\left(\sigma_{f i}^{2} \cdot \sigma_{f j}^{2}\right)^{1 / 2}$

where, $\operatorname{cov}_{f(i, j)}, \sigma_{f i}^{2}, \quad \sigma_{f f}^{2}$ are estimate of family covariance component between the $i$ th measurement and the $j$ th measurement, those of family variance component at the $i$ th measurement and at the jth measurement, respectively.

\section{Modeling time trend of genetic parameters}

In order to evaluate efficiency of early selection, genetic gain at rotation age and those due to indirect selection at early ages should be estimated, however, available genetic parameters in this study were those until 3-year old that was less than half of the assumed rotation of 8 years. Therefore regression equations relating standard deviations of genetic parameters to their mean height were derived. This is because variances tend to be dependent to their means (Falconer,1981).

The height growth curves for the two populations were calculated separately by fitting data of each the two seedling seed orchards to Chapman-Richards function (Richards, 1959, Pienaar and Turnbull, 1973):

$h_{1}\left(t_{i}\right)=A 1-\exp \left(-b t_{i}\right)^{c}$

where $h_{1}\left(t_{i}\right)$ is the average height at age $i$ months. $A$ is an upper asymptote, $b$ is a rate-of-growth parameter, $c$ is a shape-of-curve parameter and $t_{i}$ is stand age $i$ in months. The height growth, including the measured value and the predicted one, up to the rotation ages were then used to predict the estimates of genetic parameters for the two populations.

Variance and correlations estimated from each periodical measurement were regressed to their mean height to express their trend during the rotation age. Phenotypic and genetic variances were converted to the square root $(y)$, and then they are regressed to their mean height ( $h t$ ) using the following equation:

$y=a^{*}(b t)^{b}$.

where, $a$ and $b$ are constants and power coefficient, respectively. In the case of genetic correlations between measurement at $t_{i}$ and that of $t_{j}\left(r_{g i j}\right)$, they are regressed to a rate of the mean height at $t_{i}$ to that of $t_{j}$ using the following equation in order that the correlation can be 1.0 when the rate is equal to 1.0:

$r_{g i j}=1+b 1 /\left(b t_{i} / b t_{j}\right)-1$

where, $b$ is a regression coefficient, $b t_{i}$ and $b t_{j}$ are the average height at the $i$ th measurement and the $j$ th measurement $\left(b t_{i}>b t_{j}\right)$.

\section{Genetic gain and selection efficiency}

Genetic gain and selection efficiency (SE) were calculated using the results of estimates genetic 
parameters for the two populations. Selection efficiency (SE) based on gain per year was calculated as ratio of gains predicted by indirect selection on earlier ages $\left(C G_{j i}\right)$ to the gains predicted by direct selection on rotation age $\left(G_{1}\right)$, using formulas as follows (Lambeth, 1980):

$$
\begin{aligned}
& G_{l}=i_{r} h_{l}^{2} \cdot \sigma_{p l} \ldots \ldots \ldots \ldots \ldots \ldots \ldots \ldots \ldots \ldots \ldots \ldots \ldots \ldots \ldots(7) \\
& C G_{j l}=i_{j} r_{g i l} h_{j} h_{r} \sigma_{p l} \\
& S E=C G_{j l} /(j+t) / G_{l} /(l+t) \\
& =i_{j} r_{j l l} h_{j} h_{r} \sigma_{p l} /(j+t) / i_{r} h_{l}^{2} \cdot \sigma_{p l} /(l+t)
\end{aligned}
$$

where, $i_{j} i_{l}$ is the selection intensity at age $j$ and $l$, respectively, $r_{g l}$ is genetic correlation between height at age $j$ and $l, h_{l}^{2}$ is heritability for height at age $l, h_{p} h_{l}$ are square root of the heritability at ages $j$ and $l, \sigma_{p l}$ is phenotypic standard deviation at age $l, t$ is the time required to complete the breeding cycle (assuming $t=3$ years). In this study, selection intensity was assumed to be 1.0 for the convenient of calculations.

\section{RESULTS AND DISCUSSION}

\section{A. Age trend of genetic parameters}

The results of fitting height growth curve and the projection until the rotation age for the two populations are shown in Figure 1. The estimates of the three parameters of Chapman-Richards function are given in Table 2. Height growth of FNQ population was slightly better than that of PNG population in the early beginning half of the rotation, while it may be overtaken by the PNG in the latter half of rotation according to the projection. The projected heights at rotation age were $18.5 \mathrm{~m}$ for PNG and $17.5 \mathrm{~m}$ for FNQ.

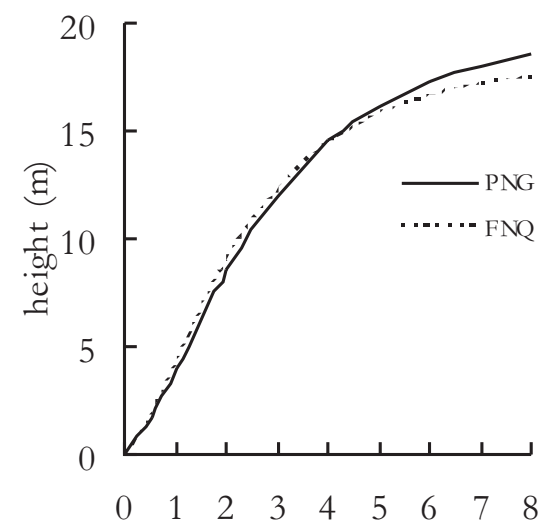

Figure 1. Height growedb (catives for PNG and FNQ resulted from the fitting data of periodical measurement in each of the two seedling seed orchards. The growth curves were fitted with Chapman Richards function (Equation 4) and their estimated parameters are given in Table 2.

Table 2. Estimates of the three parameters of Chapman-Richards function (Equation 4) fitted to the average height growth in the two populations.

\begin{tabular}{lccc}
\hline & Population & \multicolumn{3}{c}{ Parameter } \\
\cline { 2 - 4 } & $A$ & $b$ & $c$ \\
\hline PNG & $19.45(5.669)$ & $0.0359(0.0217)$ & $1.4905(0.482)$ \\
FNQ & $17.93(2.792)$ & $0.0434(0.0166)$ & $1.5654(0.397)$ \\
\hline
\end{tabular}

\begin{tabular}{|c|c|c|c|c|c|c|c|}
\hline \multirow{2}{*}{ Variance components } & \multicolumn{7}{|c|}{ Ages (months after planting) } \\
\hline & 4 & 8 & 12 & 16 & 24 & 32 & 36 \\
\hline \multicolumn{8}{|l|}{$\overline{\mathrm{PNG}}$} \\
\hline Family variance & $0.0021 * *$ & $0.0067 * *$ & $0.0098^{* *}$ & $0.0148^{* *}$ & $0.0470 * *$ & $0.0485^{* *}$ & $0.0504^{* *}$ \\
\hline Error variance & 0.0256 & 0.1308 & 0.3407 & 0.4721 & 0.7276 & 0.7240 & 0.9238 \\
\hline \multicolumn{8}{|l|}{ FNQ } \\
\hline Family variance & $0.0023^{* *}$ & $0.0092^{* *}$ & $0.0280 * *$ & $0.0483^{* *}$ & $0.0982^{* *}$ & $0.0980 * *$ & $0.0761 * *$ \\
\hline Error variance & 0.0232 & 0.1132 & 0.3156 & 0.5153 & 0.5569 & 0.9623 & 0.8451 \\
\hline
\end{tabular}

Note: Parameters : $A, b, c$ are those in Equation (3). Values in parenthesis are the standard errors to the parameters.

Table 3. A summary of the analysis of variance estimated from pooled analysis for seven ages of measurement

**Significant at the $1 \%$ level 
The results of pooled estimates of variance are summarized in Table 3. Family variations were highly significant for all the periodical measurements in the two populations. Standard deviations for phenotypic and genetic variances increased almost in proportion to the stand height in both populations (Figure 2) and they were fitted fairly well by the Equation 5, with a correlation coefficient exceeding 0.9. This suggests that those equations could be used for the prediction purposes. The size of phenotypic variance was almost the same between PNG and FNQ populations, while they were apparently different in genetic variance; that of FNQ got larger than the PNG with the increase in mean height as indicated by the regression coefficient: 0.81 for FNQ and 0.72 for PNG. Once the regression equations for both the genetic variance and phenotypic variance were determined, individual tree heritability was then calculated as a ratio of the genetic variance to the phenotypic variance.

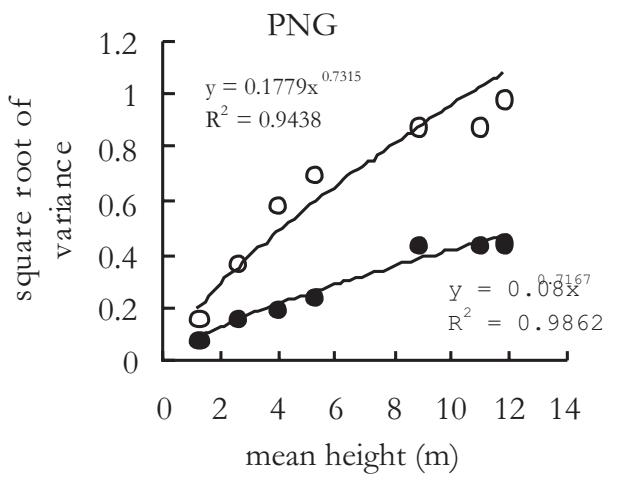

The distributions of age-age genetic correlation to the height rate are shown in Figure 3. The correlations with the height rate close to 1.0 were generally high, and they tended to decrease with the increase in the rate. This decreasing trend of age-age correlation seemed to be well expressed with the Equation 6, although the coefficients of determination were not sufficiently high due to unstable genetic correlations in the range of 1.0 to 4.0 height rate. The asymptotes for the minimum correlation, which were calculated as one minus the regression coefficient according to the nature of Equation 6, were 0.395 for PNG and 0.488 for FNQ. This indicates that juvenile-mature correlation of $A$. mangium would be fairly strong in both populations.

The projected time trends of heritability and genetic correlation, which were calculated using Equation 5 and 6 based on the predicted height growth until the rotation age, are shown in Figure 4. Trend of heritability showed fairly stable

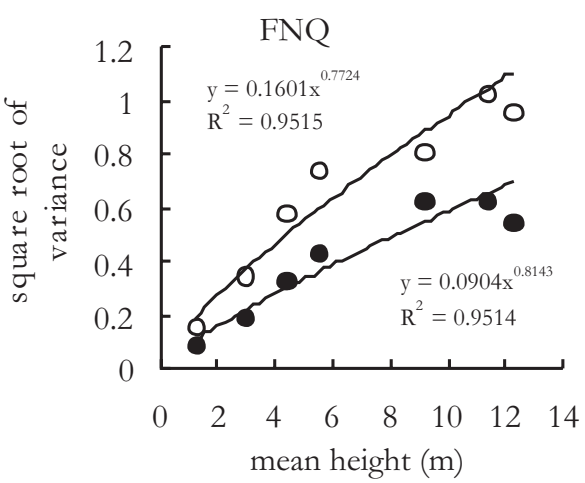

Figure 2. Relationship between mean height and square root of phenotypic variances (open circles) and that of genetic variances (closed circles) in PNG and FNQ populations.
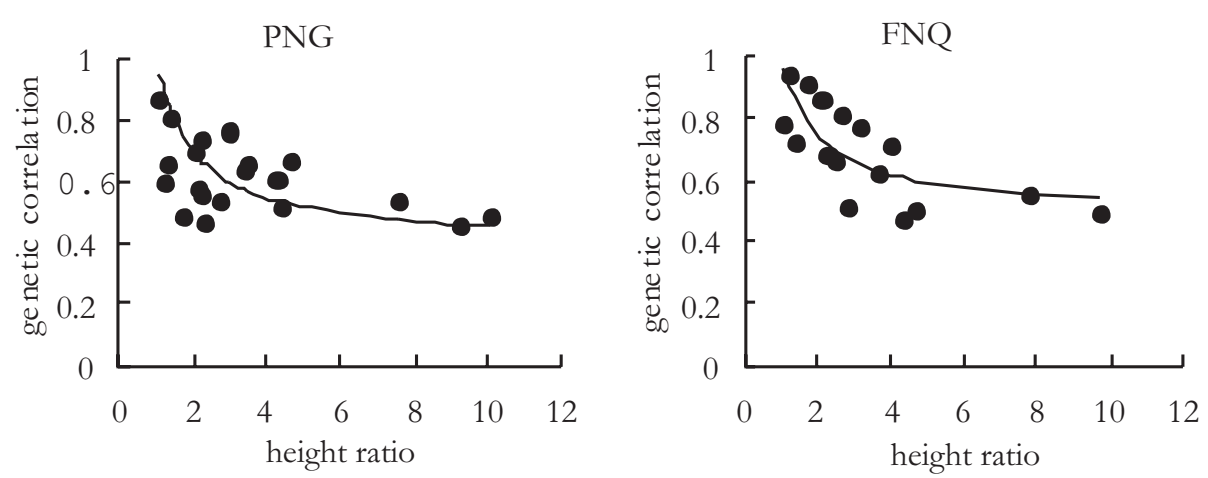

Figure 3. Change of genetic correlations with height ratio. The solid lines are fitted with Equation 6 to illustrate the trend of change. The regression equations are :

$r_{g i j}=1+0.6051 /\left(h t_{i} / h t_{j}\right)-1$ with $r^{2}=0.28$ for PNG, and $r_{g i j}=1+0.5121 /\left(b t_{i} / b t_{j}\right)-1$ with $r^{2}=0.49$ for FNQ. 
throughout the rotation, although there was an apparent difference in the magnitude of heritability, remained almost the same at around 0.19 for PNG, and gradually increased from 0.36 to 0.40 for FNQ. On the other hand, the genetic correlations showed a similar trend of change; increased rapidly starting at around 0.5 for PNG and 0.6 for $F N Q$, then exceeding 0.9 at age 4 years in both populations.

Corresponding to the finding of this study, stable ratios of genetic to phenotypic variance with advancing stand age have been reported in a range of species: Scots pine (Hannrup et al., 1998), loblolly pine (Lambeth et al., 1983, Foster, 1986), three tropical pines (Vasquez and Dvorak, 1996), Douglas-fir (Bastien and Roman-Amat, 1990), lodgepole pine (Xie and Ying, 1996), and Norway spruce (Bentzer et al., 1989). Regarding the use of wood quality as well as their correlation to the growth trait for assessing age-age correlation and early selection has been also reported for Douglasfir (Vargas-Hernandez and Adams, 1992), Radiate pine (Kumar and Lee, 2002), and Eucalyptus globulus (Stackpole et al., 2010). On the other hand, information on the use of tree height data as the predictor of genetic correlation has never been tried clearly, because most of studies had just followed the Lambeth's procedure (Lambeth, 1980) of natural logarithmic of juvenile-mature age ratio (Xiang et al., 2003, Lambeth and Dill, 2001, King and Burdon, 1991, Cotteril and Dean, 1988, Johnson et al., 1997). Although they were not described in detail, some studies indicated that the use of height ratio as the predictor of genetic correlation could potentially give better fit according to the study in loblolly pine (Gwaze et al., 2000), and Scots pine (Jansson et al., 2003). This is because the variances tend to be dependent to their mean height (Falconer, 1981), hence the procedure to estimate genetic correlation using height ratio as predictor would be a possible alternative of the log age rate (Lambeth, 1980).

The trend of genetic parameters in this study showed that the developed model in Equation 5 and 5 could facilitate the prediction of variance and correlation in $A$. mangium, particularly when there are no data available to allow these parameters to be directly estimated. This is with assumption that height growth and their future projection throughout rotation age is available. In addition, the developed model here seems also to have captured the biological norm of age trends in genetic parameters, that is, stable along the ages for heritability, and decline with increasing age interval for genetic correlation. Thus the use of tree height data as a predictor in finding the time trend of genetic parameters could be of considerable advantage to determine the accuracy of early selection.

\section{B. Genetic gain and selection efficiency}

The results of gain prediction and efficiency of early selection are shown in Figure 5. Genetic gain by indirect selection, which was calculated with Equation 8, increased with age in the two populations. Genetic gains in FNQ population were twice larger than those in PNG population. This difference in genetic gain is mainly due to the higher heritability in FNQ population, while a little higher genetic correlation might also contribute to the greater gain in FNQ population.

Efficiency of early selection based on gain per year calculated with Equation 9 shows a similar pattern both in PNG and FNQ populations. The efficiency values for all earlier ages were more than 1.0, with the highest value at 2-year old in both populations (Figure 5). This indicates that early selection would bring greater gain per year than the later direct selection at rotation age, and 2 years of age was regarded as optimum for selection to turn over the generation. This similar pattern of the efficiency in the two populations is probably due to the similar trend of genetic correlations as well as the stable trend of heritability as shown in Figure 4.

In this study of $A$. mangium, the optimum age for early selection was younger as compared to other studies reported on the fast growing species; optimum age at 4 years for E. globulus (Borralho et al., 1992), selection at older ages will lead higher gain than at younger age for E. teriticornis (Otegbeye, 1991). However, these results were obtained under the assumption different from our study; time required to complete a breeding cycle was assumed as 5 years for Eucalyptus, while it was only 3 years in this study. In the case of $A$. mangium, flowering and fruiting age come earlier than eucalyptus. Hence, 3 years would be enough to complete breeding cycle as long as using open pollinated seed for the next generation population. Therefore tree improvement program with five years per generation, consisting of 2 years for 

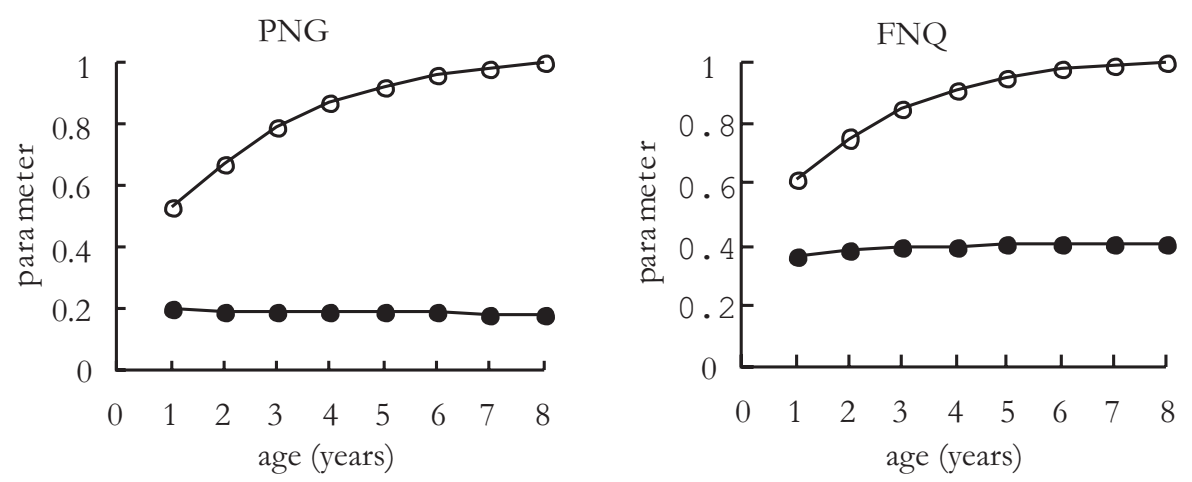

Figure 4. Age trend of genetic correlation (open circles) and heritability (closed circles) assuming 8 years of rotation.
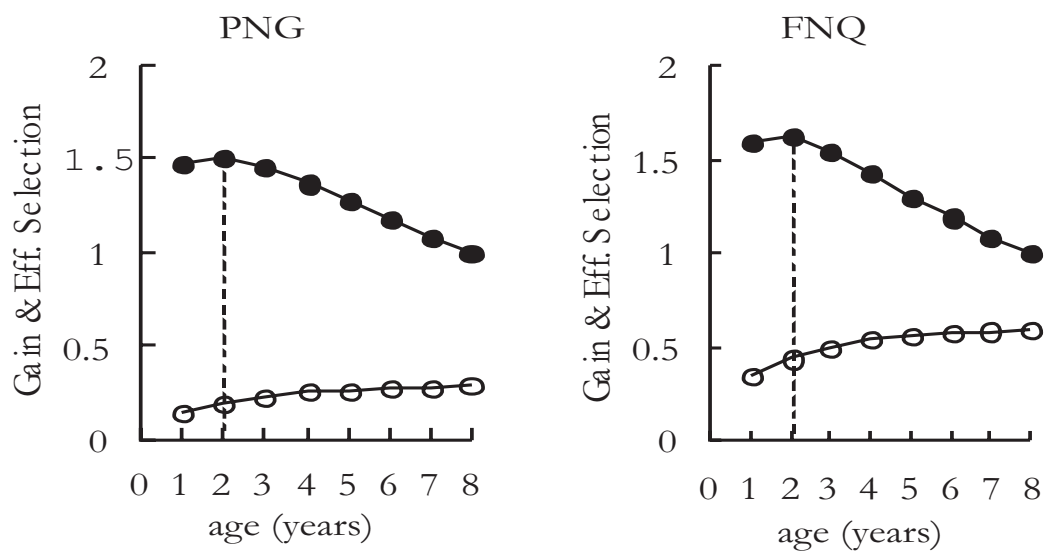

Figure 5. Predicted genetic gain by indirect selection (open circles) and the efficiency of early selection (closed circles). Gain was calculated using Equation 8, while the efficiency of selection was made with Equation 9.

selection and another 3 years to complete breeding cycle, would be feasible and optimal in terms of gain per year for $A$. mangium.

According to the results in this study, genetic correlation between early ages and the rotation was considered fairly strong in $A$. mangium, hence we can expect good amount of gain from the selection at an early ages. This would provide the grounds to justify the effectiveness of early thinning currently practiced in seedling seed orchards; however, the result on the optimum age for selection, only two years after planting, should be interpreted with caution. This is because the two years' performance is formed only under free growth phase before the canopy closer of $A$. mangium plantation. Therefore it might be desirable to continue observation of candidate plus trees for few more years to confirm their later performances before seed collection.

\section{CONCLUSION}

1. A model with the use of tree height data as the predictor in finding the time trend of genetic parameters was well developed.

2. Trend of heritability along the rotation ages were almost stable at around 0.19 for PNG, and gradually increased from 0.36 to 0.40 for FNQ. Genetic correlation between early ages and the rotation age rapidly increased and it exceeded 0.9 at age 4 years in the two populations.

3. Early selection based on tree height will bring more gain per year than later direct selection on 8 years of rotation age in both populations, with an optimal age for early selection found at age 2 years in the two populations. 


\section{V.ACKNOWLEDGEMENT}

The authors would like to thank The Centre for Forest Biotechnology and Tree Improvement (CFBTI), Forest Tree Improvement Project-JICA (Japan International Cooperation Agency), and PT Inhutani III for establishing the seedling seed orchard. Appreciation is also extended to the Faculty of Agriculture, Kyushu University Japan for valuable support during the study.

\section{REFERENCES}

Bastien, J.C. and B. Roman-Amat. 1990. Predicting Douglas-fir (Psendotsuga menziesii (Mirb.) Franco) volume at age 15 with early traits. Silvae Genetica 39:29-35.

Bentzer, B.G., G.S. Foster, A.R. Hellberg and A.C. Podzorski. 1989. Trend in genetic and environmental parameter, genetic correlation, and response to indirect selection for 10-year volume in a Norway spruce clonal experiment. Canadian Journal of Forest Research 19:897-903.

Borralho, N.M.G., P.P. Cotterill and P.J. Kanowski. 1992. Genetic control of growth of Eucalyptus globulus in Portugal. II. Efficiencies of early selection. Silvae Genetica 41:70-77.

Cotteril, P.P. and C.A. Dean. 1988. Change in the genetic control of growth of radiate pine to 16 years and efficiencies of early selection. Silvae Genetica 38:138-146.

Falconer, D.S. 1981. Introduction to quantitative genetics. $2^{\text {nd }}$ Edition, Longman House, London, UK, pp340.

Foster, G.S. 1986. Trends in genetic parameters with stand developmet on their influence on early selection for volume growth in loblolly pine. Forest Science 32:944-959.

Gwaze, D.P., T.D. Bridgwater, J.A. Byram, J.A. Woolliams and C.G. Williams. 2000. Predicting age-age genetic correlation in tree-breeding programs: A case study of Pinus taeda L. Theoretical and Applied Genetics 100:199-206.

Hannrup, B., L. Wilhelmsson and O. Danell. 1998. Time trends for genetic parameter of wood density and growth traits in Pinus sylvetris L. Silvae Genetica 47:214-219.

Hodge, G.R. and R.C. Purnell. 1993. Genetic parameter estimates for wood density, transition age, and radial growth in slash pine. Canadian Journal of Forest Research 23(9):1881-1891.

Jansson, G., B. Li and B. Hannrup. 2003. Time trends in genetic parameter for height and optimal age for parental selection in Scots pine. Forest Science 49:696-705.

Johnson, G.R., R.A. Sniezko and N.L. Mandel. 1997. Age trends in Douglas-fir genetic parameter and implications for optimum selection age. Silvae Genetica 46:349-358.

King, J.N. and R.D. Burdon. 1991. Time trends in inheritance and projected efficiencies of early selection in a large 17-year-old progeny test of Pinus radiate. Canadian Journal of Forest Research 21:1200-1207.

Kumar, S. and J. Lee. 2002. Age-age correlations and early selection for end-of-rotation wood density in Radiata pine. Forest Genetics 9:323-330.

Lambeth, C.C. 1980. Juvenile-mature correlations in Pinaceae and implications for early selection. Forest Science 26:571-580.

Lambeth, C.C., J.P. van Buijtenen, R.B. McCulliough and S.D. Duke. 1983. Early selection is effective in 20-year-old genetic tests of loblolly pine. Silvae Genetica 32:210-215.

Lambeth, C.C. and L.A. Dill. 2001. Prediction models for juvenile-mature correlations for loblolly pine growth traits within, between and across test sites. Forest Science 8:101108.

Leksono B., S. Kurinobu and Y. Ide. 2006. Optimum age for selection based on a time trend of genetic parameters related to diameter growth in seedling seed orchards of Eucalyptus pellita in Indonesia. Journal of Forest Research 11:359-364.

McKeand, S. 1988. Optimum age for family selection for growth in genetic test of loblolly pine. Forest Science 34:400-411.

Otegbeye, G.O. 1991. Age trends in the genetic control of stem diameter of Eucalyptus 
tereticornis and the Implication for selection. Silvae Genetica 40:85-87.

Pienaar, L.V. and K. J. Turnbull. 1973. The Chapman-Richards generalization of von Bertalanffy's growth model for basal area growth and yield in even-aged stands. Forest Science 19:2 - 22.

Richards, F.J. 1959. A flexible growth function for empirical use. Journal of Experimental Botany 10:290 - 300.

Stackpole, J., R.E. Vaillancourt, M. Aguigar and B.M. Potts. 2010. Age trends in genetic parameters for growth and wood density in Eucalyptus globulus. Tree Genetics and Genomes 6:179-193.

Vargas-Hernandez, J. and W.T. Adams. 1992. Ageage correlation and early selection for wood density in young coastal Douglas-fir.. Forest Science 38:467-478.
Vasquez, J. and W.S. Dvorak. 1996. Trends in variance and heritabilities with stand development of tropical pines. Canadian Journal of Forest Research 26:1473-1480.

Woolaston R.R., P.J. Kanowski and G. Nikles. 1990. Genetic parameter estimates for Pinus caribaea var. hondurensis in coastal Queensland, Australia. Silvae Genetica 39:21-28.

Xiang, B., B. Li, and S. McKeand. 2003. Genetic gain and selection efficiency of loblolly pine in three geographic regions. Forest Science 49:196-208.

Xie, C.Y. and C.C. Ying. 1996. Heritabilities, ageage correlation, and early selection in lodgepole pine (Pinus contorta ssp. Latifolia). Silvae Genetica 45:101-107.

Zobel, B.J. and J. Talbert. 1984. Applied forest tree improvement. John Wiley \& Sons. New York. 